\title{
The Association of Urine Microalbumin and Pulse Pressure in Korean Adults
}

\author{
Mee Young Gee ${ }^{1}$, Hyun Yoon ${ }^{2}$ \\ ${ }^{1}$ Department of Nursing, Christian College of Nursing, Gwangju 61662, Korea \\ ${ }^{2}$ Department of Biomedical Laboratory Science, Hanlyo University, Gwangyang 57764, Korea
}

\section{한국 성인에서 뇨 중 Microalbumin과 맥압의 관련성}

\author{
기미영 ${ }^{1}$, 윤 현 $^{2}$ \\ ${ }^{1}$ 광주기독간호대학교 간호학과, ${ }^{2}$ 한려대학교 임상병리학과
}

\begin{abstract}
The aim of this study was to assess the association between microalbumin and pulse pressure (PP) in Korean adults. The study subjects were Korean adults 20 years or older $(n=4,948)$ who participated in the Korea National Health and Nutrition Examination Survey 2012. The urine microalbumin level $(\mathrm{M} \pm \mathrm{SE})$ was significantly higher $(p=0.047)$ in the high PP group (PP $>60.0$ $\mathrm{mmHg}$ ) $[33.02 \pm 4.93 \mu \mathrm{g} / \mathrm{mL}$ (95\% confidence interval $(\mathrm{Cl}), 23.37 \sim 42.68)]$ than the normal PP group (PP $\leq 60.0 \mathrm{mmHg})[22.57 \pm 1.63 \mu \mathrm{g} / \mathrm{mL}(95 \% \mathrm{Cl}, 19.36 \sim 25.77)]$, after adjusting for age, gender, smoking, drinking, regular exercising, WM, BMI, TC, TG, HDL-C, FBG, BUN, creatinine, and urine creatinine. In conclusion, pulse pressure was associated with the microalbumin level in Korean adults.
\end{abstract}

Key words: Microalbumin, Pulse pressure

This is an Open Access article distributed under the terms of the Creative Commons Attribution Non-Commercial License (http://creativecommons.org/licenses/by-nc/4.0) which permits unrestricted non-commercial use, distribution, and reproduction in any medium, provided the original work is properly cited.

Copyright ( 2016 The Korean Society for Clinical Laboratory Science. All rights reserved.
Corresponding author: Hyun Yoon

Department of Biomedical Laboratory Science, Hanlyo University, 94-13, Hallyeodae-gil, Gwangyang-eup, Gwangyang 57764, Korea Tel: 82-61-760-1150

Fax: 82-61-761-6709

E-mail:yh9074@yahoo.co.kr

Received: July 20, 2016

Revised $1^{\text {st: }}$ August 7, 2016

Revised $2^{\text {nd. }}$ : August 18, 2016

Revised 3 ${ }^{\text {rd: }}$ : August 23, 2016

Revised $4^{\text {th: }}$ : August 25, 2016

Accepted: August 25, 2016

\section{서 론}

미세알부민뇨(microalbuminuria)는 단백뇨(proteinuria)가 배 설되기 전에 미세한 양의 알부민이 배설되는 것으로[1], 향후 단백 뇨를 동반한 당뇨병성 신증을 예측하는 지표가 될 수 있다[2,3].

맥압(Pulse pressure, PP)은수축기혈압(systolic blood pressure, $\mathrm{SBP}$ )과 이완기혈압(diastolic blood pressure, $\mathrm{DBP}$ )의 차이로 정 의되며, 동맥의 탄성과 파장반사로 결정되기 때문에 동맥 경직도가 증가할수록 증가한다[4]. 동맥 경직도 증가의 위험인자로는 연령, 당뇨, 고혈압, 대사증후군 및 죽상경화증 등이 있다[5-7]. 특히, 맥 압은 만성 신질환의 진행과 관련이 있으며 [8], 당뇨의 발생에 있어 서 강력한 예측인자로 각광을 받고 있다[9]. 그러나, 이와 같은 만성
신질환의 진행 및 당뇨발생의 예측인자인 맥압과 당뇨병성 신증의 예측인자인 뇨 중 microalbumin의 관련성에 대한 연구는 거의 없 다. 따라서 본 연구는 제 5 기 국민건강영양조사자료를 이용하여 대 한민국 성인에서 뇨 중 microalbumin과 맥압의 관련성에 대하여 알아보고자 하였다.

\section{재료 및 방법}

\section{1. 연구대상}

본 연구는 질병관리본부 주관으로 시행된 국민건강영양조사 (2012년)의 자료를 이용하였다. 조사 참여자수는 8,058명이었고, 이 중에서 20세 이상 성인은 6,221 명이었다. 본 연구 대상자는 
6,221명 중 건강 설문에서 불충분한 응답(362명)과 혈압, 혈액 및 뇨 중 microalbumin 등의 검사결과가 누락(911명)이 되어있는 대 상자 1,273 명을 제외한 총 4,948 명을 최종 분석 대상자로 하였다. 제 5 기 3차년도 국민건강영양조사자료는 질병관리본부 연구윤리심의 위원회의 심의 및 승인을 받았다(승인번호; 2012-01EXP-01-2C).

\section{2. 자료수집}

본 연구는 2012년도부터 1월부터 12월까지 12개월 동안 시행 된 제 5기 국민건강영양조사 자료를 이용하였다. 조사항목으로는 대상자들의 성별, 연령, WM, BMI, 안정 시 혈압 및 맥압, 아침공복 시의 혈액검사, 뇨 중 creatinine과 microalbumin 등이었다.

\section{3. 대상자의 특성}

\section{1) 일반적 특성 및 혈액화학검사}

대상자 중 연령은 평균값으로, 성별은 남녀로 구분하였다. 신체 계측은 체질량지수(body mass index, BMI), 허리둘레(waist measurement, WM), SBP, DBP의 측정값을 사용하였다. 혈액화 학검사는 총 콜레스테롤(total cholesterol, TC), 중성지방(triglyceride, TG), 고밀도 콜레스테롤(HDL-cholesterol, HDL-C), 공 복 시 혈당(fasting blood glucose, FBG), 혈중 요소질소(blood urea nitrogen, BUN) 및 creatinine의 측정값을 사용하였고, 뇨 중 creatinine과 microalbumin의 측정값을 사용하였다.

2) 맥압 및 microalbumin

맥압은 $\mathrm{SBP}$ 에서 $\mathrm{DBP}$ 를 차감하여 계산하였고, $\mathrm{PP} \leq 60.0$ $\mathrm{mmHg}$ 를 Normal PP로, PP $>60.0 \mathrm{mmHg}$ 를 High PP로 구분하였 다[10]. 뇨 중 microalbumin의 사분위는 1 사분위 $(<2.60 \mu \mathrm{g} / \mathrm{mL})$,

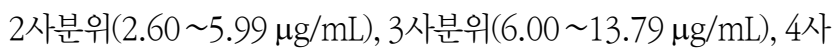
분위 $(\geq 13.80 \mu \mathrm{g} / \mathrm{mL})$ 로 구분하였다.

\section{4. 자료처리 및 분석}

자료의 통계처리는 SPSS WIN version 18.0 (SPSS Inc., Chicago, IL, USA) 통계프로그램을 이용하였다. 대상자의 특성에 대한 분포는 빈도와 백분율로 나타내었고 연속형 자료는 평균과 표 준편차로 표시하였다. 뇨 중 microalbumin의 사분위에 따른 특성 은 교차분석과 ANOVA test를 이용하여 분석하였고, ANCOVA test에서 네 가지의 Model을 실시하여 PP가 뇨 중 microalbumin 에 독립적으로 영향을 주는지를 알아보았다. Model 1은 연령과 성 별을 보정하였고, Model 2는 Model 1에 추가적으로 흡연, 음주, 규 칙적인 운동을 보정하였다. Model 3은 Model 2에 추가적으로 WM, BMI, TC, TG, HDL-C를 보정하였고, Model 4는 Model 3에
추가적으로 FBG, creatinine, 요 중 creatinine을 보정하였다. 모 든 통계량의 유의수준은 $p<0.05$ 로 판정하였다.

\section{결 과}

\section{1. 연구대상자의 일반적 특성}

연구대상자의 일반적 특성은 Table 1 과 같다. 본 연구의 총 연구대 상자는 4,948명이었고, 남성은 2,174명(43.9\%), 여성은 2,754명 (56.1\%)이었다. 전체 대상자 중, High PP에 해당되는 대상자는 543 명(11.0\%)이었고, 뇨 중 microalbumin의 평균값은 $23.71 \pm 113.78$ $\mu \mathrm{g} / \mathrm{mL}$ 이었다.

\section{2. 뇨 중 microalbumin의 사분위에 따른 대상자들의 임상적 특성}

뇨 중 microalbumin의 사분위에 따른 대상자들의 임상적 특성은 Table 2 와 같다. 뇨 중 microalbumin의 사분위에서 유의한 차이를 보이는 변수는 연령 $(p<0.001), \operatorname{SBP}(p<0.001), \operatorname{DBP}(p<0.001)$, $\operatorname{PP}(p<0.001), \operatorname{BMI}(p<0.001), \operatorname{WM}(p<0.001), \mathrm{TG}(p<0.001)$, HDL-C $(p<0.001), \mathrm{FBG}(\mathrm{p}<0.001), \mathrm{BUN}(p<0.001)$, creatinine $(p<0.001)$ 및 뇨 중 creatinine $(p<0.001)$ 등이었고, 성별 ( $p=0.093)$, 흡연습관 $(p=0.175)$, 음주습관 $(p=0.227)$, 운동습관 $(p=0.075), \mathrm{TC}(p=0.715)$ 등은 유의한 차이를 보이지 않았다.

Table 1. General characteristics of research subjects $(n=4,948)$

\begin{tabular}{lcc}
\hline \multicolumn{1}{c}{ Variables } & Category & $\mathrm{n}(\%), \mathrm{M} \pm \mathrm{SD}$ \\
\hline Age (year) & & $51.88 \pm 16.02$ \\
Gender & Males & $2,174(43.9)$ \\
Smoking & Current smoker & $1,020(20.6)$ \\
Drinking & Yes & $2,495(50.4)$ \\
Regular exercising & Yes & $628(12.7)$ \\
BMI $\left(\mathrm{kg} / \mathrm{m}^{2}\right)$ & & $23.84 \pm 3.34$ \\
WM $(\mathrm{cm})$ & & $81.50 \pm 9.58$ \\
SBP $(\mathrm{mmHg})$ & & $120.08 \pm 16.98$ \\
DBP $(\mathrm{mmHg})$ & & $75.91 \pm 10.49$ \\
PP $(\mathrm{mmHg})$ & & $44.18 \pm 13.80$ \\
High PP & & $543(11.0)$ \\
TC $(\mathrm{mg} / \mathrm{dL})$ & & $190.51 \pm 36.11$ \\
TG $(\mathrm{mg} / \mathrm{dL})$ & & $131.13 \pm 87.19$ \\
HDL-C $(\mathrm{mg} / \mathrm{dL})$ & $51.52 \pm 12.63$ \\
FBG $(\mathrm{mg} / \mathrm{dL})$ & $98.92 \pm 21.78$ \\
BUN $(\mathrm{mg} / \mathrm{dL})$ & & $14.65 \pm 4.49$ \\
Creatinine $(\mathrm{mg} / \mathrm{dL})$ & & $0.84 \pm 0.23$ \\
Urine $\mathrm{creatinine}(\mathrm{mg} / \mathrm{dL})$ & & $150.10 \pm 84.99$ \\
Microalbumin $(\mu \mathrm{mg} / \mathrm{mL})$ & $23.71 \pm 113.78$ \\
\hline
\end{tabular}

Abbreviation: BMI, body mass index; WM, waist measurement; $\mathrm{SBP}$, systolic blood pressure; DBP, diastolic blood pressure; PP, pulse pressure; TC, total Cholesterol; TG, triglyceride; HDL-C, High density lipoprotein cholesterol; FBG, fasting blood glucose; BUN, blood urea nitrogen. 
Table 2. Clinical characteristics of subjects in relation for microalbumin quartile

\begin{tabular}{|c|c|c|c|c|c|}
\hline Variables & $\begin{array}{c}\text { Quartile } 1 \quad(n=1,235) \\
(<2.60 \mu \mathrm{g} / \mathrm{mL})\end{array}$ & $\begin{array}{l}\text { Quartile } 2(\mathrm{n}=1,218) \\
(2.60 \sim 5.99 \mu \mathrm{g} / \mathrm{mL})\end{array}$ & $\begin{array}{l}\text { Quartile } 3(n=1,250) \\
(6.00 \sim 13.79 \mu \mathrm{g} / \mathrm{mL})\end{array}$ & $\begin{array}{l}\text { Quartile } 4(\mathrm{n}=1,245) \\
(\geq 13.80 \mu \mathrm{g} / \mathrm{mL})\end{array}$ & $p$-value \\
\hline Age (years) & $50.94 \pm 14.83$ & $50.83 \pm 15.44$ & $50.25 \pm 16.31$ & $55.47 \pm 16.89$ & $<0.001$ \\
\hline Gender (Males) & $505(40.9)$ & $553(45.4)$ & $556(44.5)$ & $560(45.0)$ & 0.093 \\
\hline Current smoker & $247(20.0)$ & $254(20.9)$ & $250(20.0)$ & $269(21.6)$ & 0.175 \\
\hline Drinker & $618(50.0)$ & $643(52.8)$ & $628(50.2)$ & $606(48.7)$ & 0.227 \\
\hline Regular exerciser & $183(14.9)$ & $142(11.7)$ & $152(12.2)$ & $151(12.2)$ & 0.075 \\
\hline $\mathrm{SBP}(\mathrm{mmHg})$ & $116.84 \pm 15.53$ & $118.28 \pm 15.99$ & $119.17 \pm 16.03$ & $125.99 \pm 18.70$ & $<0.001$ \\
\hline $\mathrm{DBP}(\mathrm{mmHg})$ & $74.38 \pm 9.57$ & $75.30 \pm 10.00$ & $76.21 \pm 9.94$ & $77.71 \pm 11.98$ & $<0.001$ \\
\hline $\mathrm{PP}(\mathrm{mmHg})$ & $42.45 \pm 12.25$ & $42.98 \pm 12.73$ & $42.95 \pm 12.86$ & $48.28 \pm 16.17$ & $<0.001$ \\
\hline BMI $\left(\mathrm{kg} / \mathrm{m}^{2}\right)$ & $23.56 \pm 3.02$ & $23.64 \pm 3.15$ & $23.78 \pm 3.41$ & $24.36 \pm 3.68$ & $<0.001$ \\
\hline WM (cm) & $80.45 \pm 5.88$ & $80.92 \pm 9.04$ & $81.21 \pm 9.84$ & $83.39 \pm 10.23$ & $<0.001$ \\
\hline $\mathrm{TC}(\mathrm{mg} / \mathrm{dL})$ & $191.21 \pm 35.50$ & $190.32 \pm 35.69$ & $190.87 \pm 34.56$ & $189.63 \pm 38.57$ & 0.715 \\
\hline $\mathrm{TG}(\mathrm{mg} / \mathrm{dL})$ & $123.30 \pm 80.14$ & $127.43 \pm 82.36$ & $129.14 \pm 80.72$ & $144.50 \pm 102.12$ & $<0.001$ \\
\hline $\mathrm{HDL}-\mathrm{C}(\mathrm{mg} / \mathrm{dL})$ & $52.73 \pm 12.31$ & $51.62 \pm 12.67$ & $51.82 \pm 13.01$ & $49.93 \pm 12.36$ & $<0.001$ \\
\hline $\mathrm{FBG}(\mathrm{mg} / \mathrm{dL})$ & $95.62 \pm 16.62$ & $95.58 \pm 13.86$ & $97.86 \pm 20.30$ & $106.83 \pm 60.49$ & $<0.001$ \\
\hline BUN (mg/dL) & $13.94 \pm 3.91$ & $14.40 \pm 3.82$ & $14.54 \pm 4.19$ & $15.72 \pm 5.61$ & $<0.001$ \\
\hline Creatinine (mg/dL) & $0.82 \pm 0.17$ & $0.83 \pm 0.17$ & $0.83 \pm 0.17$ & $0.88 \pm 0.36$ & $<0.001$ \\
\hline Urine creatinine $(\mathrm{mg} / \mathrm{dL})$ & $88.39 \pm 44.07$ & $141.96 \pm 60.66$ & $183.51 \pm 82.36$ & $185.72 \pm 100.45$ & $<0.001$ \\
\hline
\end{tabular}

$\mathrm{n}(\%), M \pm S D,(n=4,948)$.

Abbreviation: 'See Table 1.'

Table 3. Multiple linear regression analysis evaluating the independent determinants of microalbumin $(n=4,948)$

\begin{tabular}{lccc}
\hline & $\mathrm{B}$ & $\mathrm{SE}$ & $p$-value \\
\hline Microalbumin $(\mu \mathrm{g} / \mathrm{mL})$ & & & \\
Intercept & -287.01 & 26.73 & $<0.001$ \\
Age & -0.249 & 0.133 & 0.060 \\
Males & 41.036 & 4.661 & $<0.001$ \\
Current smoker & 0.342 & 2.163 & 0.847 \\
Drinker & -3.442 & 3.411 & 0.313 \\
Regular exerciser & -10.325 & 6.295 & 0.101 \\
BMI & 0.558 & 1.000 & 0.557 \\
WM & -0.207 & 0.374 & 0.581 \\
SBP & 0.520 & 0.131 & $<0.001$ \\
DBP & 0.084 & 0.197 & 0.669 \\
TC & -0.078 & 0.048 & 0.211 \\
TG & 0.072 & 0.022 & 0.001 \\
HDL-C & 0.186 & 0.148 & 0.211 \\
FBG & 0.463 & 0.075 & $<0.001$ \\
BUN & 1.404 & 0.414 & 0.001 \\
Creatinine & 155.954 & 8.498 & $<0.001$ \\
Urine creatinine & 0.054 & 0.020 & 0.014 \\
\hline
\end{tabular}

Abbreviation: 'See Table 1.'

\section{3. 뇨 중 microalbuminn에 영향을 미치는 요인}

뇨 중 microalbumin에 영향을 미치는 요인은 Table 3과 같다. 뇨 중 microalbumin의 평균값에 독립적으로 영향을 미치는 변수 는성별 $(p<0.001), \operatorname{SBP}(p<0.001), \mathrm{TG}(p=0.001), \operatorname{FBG}(p<0.001)$, $\operatorname{BUN}(p=0.001)$, creatinine $(p<0.001)$ 및 뇨 중 creatinine ( $p=0.014)$ 등이었고, 연령 $(p=0.060)$, 흡연습관 $(p=0.847)$, 음주습 관 $(p=0.313)$, 운동습관 $(p=0.101), \mathrm{BMI}(p=0.557), \mathrm{WM}(p=0.581)$,
$\operatorname{DBP}(p=0.669), \mathrm{TC}(p=0.211), \mathrm{HDL}-\mathrm{C}(p=0.211)$ 등은 독립적으 로 유의한 변수가 아니었다.

\section{PP에 따른 뇨 중 microalbumin의 평균값 비교}

$\mathrm{PP}$ 에 따른 뇨 중 microalbumin의 평균값 비교는 Table 4와 같 다. PP를 Normal PP와 High PP로 나누었을 때, 연령, 성별, 흡연습 관, 음주습관, 운동습관, $\mathrm{WM}, \mathrm{BMI}, \mathrm{TC}, \mathrm{TG}, \mathrm{HDL}-\mathrm{C}, \mathrm{FBG}, \mathrm{BUN}$, creatinine 및 뇨 중 creatinine등을 보정한 후의 결과에서 High $\mathrm{PP}$ 의 뇨 중 microalbumin평균값 $(\mathrm{M} \pm \mathrm{SE})$ 은 $33.02 \pm 4.93 \mu \mathrm{g} / \mathrm{mL}$

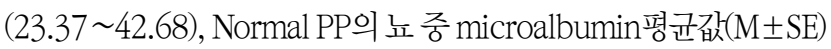
은 $22.57 \pm 1.63 \mu \mathrm{g} / \mathrm{mL}$ (19.36 25.77)로 High PP에서 유의하게 높았다 $(p=0.047)$.

\section{고 찰}

본 연구는 2012년도에 시행된 국민건강영양조사 제 5기 3차년 도 자료를 이용하여 실시한 뇨 중 microalbumin과 맥압의 관련성 에 대한 연구이다. 본 연구의 주요결과는 뇨 중 microalbumin와 관 련된 변수를 보정한 후에 High PP의 뇨 중 microalbumin평균값이 Normal PP의 뇨 중 microalbumin평균값보다 높았다.

$\mathrm{PP}$ 는 단순히 $\mathrm{SBP}$ 과 $\mathrm{DBP}$ 의 차로 환산된 수치지만, $\mathrm{PP}$ 의 증가는 동맥경화, 고지혈증, 당뇨, 죽상경화 및 이로 인한 심 • 뇌혈관질환 등을 예측하는 중요인자로 알려져 있다[9,11-13]. 맥압이 증가하 는 경우는 첫째, $\mathrm{DBP}$ 가 $\mathrm{SBP}$ 보다 상대적으로 많이 감소하는 경우로 
Table 4. Comparisons of serum microalbumin levels for PP $(n=4,948)$

\begin{tabular}{ccccc}
\hline Variables & & Normal PP & High PP & $p$-value \\
\hline Microalbumin $(\mu \mathrm{g} / \mathrm{mL})$ & Model 1 & $21.99 \pm 1.72(18.62 \sim 25.38)$ & $37.62 \pm 5.17(27.49 \sim 47.75)$ & 0.005 \\
& Model 2 & $21.96 \pm 1.72(18.58 \sim 25.34)$ & $37.94 \pm 5.17(27.80 \sim 48.09)$ & 0.004 \\
& Model 2 & $22.04 \pm 1.72(18.67 \sim 25.41)$ & $37.28 \pm 5.18(27.14 \sim 47.43)$ & 0.006 \\
& Model 4 & $22.57 \pm 1.63(19.36 \sim 25.77)$ & $33.02 \pm 4.93(23.37 \sim 42.68)$ & 0.047 \\
\hline
\end{tabular}

Model $1[\mathrm{M} \pm \mathrm{SE}(95 \% \mathrm{Cl})]$ : adjusted for age and gender. Model $2[\mathrm{M} \pm \mathrm{SE}(95 \% \mathrm{Cl})]$ : adjusted for age, gender, smoking, drinking, and regular exercising. Model 3 [M $\mathrm{ME}(95 \% \mathrm{Cl})]$ : adjusted for age, gender, smoking, drinking, regular exercising, WM, BMI, TC, TG, and HDL-C. Model $4[\mathrm{M} \pm \mathrm{SE}(95 \% \mathrm{Cl})]$ : adjusted for age, gender, smoking, drinking, regular exercising, WM, BMI, TC, TG, HDL-C, FBG, BUN, creatinine, and urine creatinine.

Abbreviation: 'See Table 1.'

큰 동맥의 경직도가 증가함으로써 발생한다고 알려져 있다[14]. 둘 째, SBP가 DBP보다 상대적으로 많이 증가하는 경우로 1회 심박출 량 또는 심실박출률(ventricular ejection rate)이 증가하여 심장기 능에 상당한 부담으로 작용할 수 있다[15]. Franklin 등은 PP가 10 $\mathrm{mmHg}$ 상승하면 $22 \%, \mathrm{SBP}$ 가 $10 \mathrm{mmHg}$ 상승하면 $16 \%, \mathrm{DBP}$ 가 10 $\mathrm{mmHg}$ 상승하면 $14 \%$ 정도 관상동맥질환이 증가한다고 하였고, $\mathrm{SBP}$ 의 상승에 의한 관상동맥질환 환자 중에서 $\mathrm{DBP}$ 가 낮을수록, $\mathrm{PP}$ 가 높을수록 사망률이 높아진다고 하였다[16]. 또한, Staessen 등은 $\mathrm{SBP}$ 가 $160 \mathrm{mmHg}$ 이상인 대상자 중에서 $\mathrm{SBP}$ 가 $10 \mathrm{mmHg}$ 증가했을 때 사망률은 $1.22(p<0.05)$ 배, 뇌졸중은 $1.22(p<0.05)$ 배 증가하고, $\mathrm{SBP}$ 의 증가로 인한 고혈압의 합병증에서도 $\mathrm{SBP}$ 의 증 가에 대하여 $\mathrm{DBP}$ 가 높으면 합병증도 낮아진다는 연구결과로 고혈 압환자에서는 $\mathrm{SBP}$ 와 $\mathrm{DBP}$ 수치도 중요하지만, $\mathrm{PP}$ 수치가 더욱 중요 하다고 기술하였다[17].

뇨 중 microalbumin의 증가는 당뇨병성 신증의 예측인자이며 [2,3], 심 - 뇌혈관질환 및 고혈압에 영향을 미치는 주요한 영향인 자이다[18,19]. Yudkin 등은 심혈관질환이 없는 대상자 중 뇨 중 microalbumin가 증가된 대상자에서 동맥의 경직도가 증가하였기 때문에 뇨 중 microalbumin의 증가는 동맥경화의 위험인자라고 하였다[20].

현재, 뇨 중 microalbumin과 $\mathrm{PP}$ 의 관련성에 대한 연구는 거의 없다. Pedrinelli 등은 211명의 이탈리아인을 대상으로 실시한 연 구에서 microalbuminuria (urine microalbumin $\geq 15 \mu \mathrm{g} / \mathrm{mL}$ )는 심혈관질환의 강력한 위험인자이며, 특히 $\mathrm{PP}$ 의 증가와 관련이 있 다고 하였다 $(p<0.001)$ [21]. 또한, Cirillo 등은 1,567명(남성, 677 명; 여성, 890 명)의 이탈리아인을 대상으로 실시한 연구에서 microalbuminuria (urine microalbumin $\geq 20 \mu \mathrm{g} / \mathrm{mL}$ )의 위험비 (Odds ratios)가 PP가 $15 \mathrm{mmHg}$ 증가할수록 1.71배(1.31 2.22) 가 증가한다고 하였다[22]. 본 연구의 선형회귀분석결과에서 $\mathrm{SBP}$, $\mathrm{TG}$ 및 FBG는 뇨 중 microalbumin의 평균값을 증가시키는 유의한 변수였지만, $\mathrm{DBP}$ 는 유의한 변수가 아니었다. TG와 $\mathrm{FBG}$ 는 $\mathrm{PP}$ 를
증가시키는 강력한 위험인자이며[23], $\mathrm{PP}$ 는 $\mathrm{SBP}$ 에서 $\mathrm{DBP}$ 를 차감 한 수치이기 때문에 $\mathrm{PP}$ 의 증가가 일어나는 첫 번째 경우인 $\mathrm{SBP}$ 의 증가로 인한 $\mathrm{PP}$ 가 증가하였기 때문으로 사료된다.

결론적으로, 대한민국 성인에서 $\mathrm{PP}$ 의 증가는 뇨 중 microalbumin 의 증가와 유의한 관련성이 있었다. 뇨 중 microalbumin과 SBP 및 $\mathrm{DBP}$ 는 인종마다 다르기 때문에 [24], 뇨 중 microalbumin과 PP의 관련성도 인종과 나라마다 다를 수 있다. 또한, 본 연구는 단면연구 이기 때문에 PP의 증가가 뇨 중 microalbumin의 증가에 영향을 주 는지, 아니면 뇨 중 microalbumin의 증가가 PP의 증가에 영향을 주는지는 알 수 없다. 따라서 이에 대한 코호트 연구를 시행할 수 있 다면 정확한 인과관계를 확인하기 위한 더욱더 정확한 결과를 얻을 수 있을 것으로 기대된다.

\section{요 약}

본 연구는 국가자료인 2012년도 국민건강영양조사 자료를 이 용하여 20세 이상 성인 $(n=4,948)$ 에서 뇨 중 microalbumin과 맥압 (Pulse pressure, PP)의 관련성을 평가하고자 실시하였다. 연구결 과에서 연령, 성별, 흡연습관, 음주습관, 운동습관, WM, BMI, TC, TG, HDL-C, FBG, BUN, creatinine, 및 요 중 creatinine 등을 보 정하였을 때, 뇨 중 microalbumin평균값에서, High PP ( $\mathrm{PP}>60.0$ $\mathrm{mmHg}$ ) $[33.02 \pm 4.93 \mu \mathrm{g} / \mathrm{mL}$ (95\% confidence interval (CI), 23.37 42.68)] 가 Normal PP ( $\mathrm{PP} \leq 60.0 \mathrm{mmHg})[22.57 \pm 1.63$ $\mu \mathrm{g} / \mathrm{mL}(95 \% \mathrm{CI}, 19.36 \sim 25.77)]$ 에 비하여 유의하게 높았다 $(p=0.047)$. 결론적으로 대한민국 성인에서 $\mathrm{PP}$ 의 증가는 뇨 중 microalbumin의 증가와 유의한 관련성이 있었다.

\section{Acknowledgements: None}

Funding: None

Conflict of interest: None 


\section{References}

1. Svendsen PA, Oxenboll B, Christiansen JS. Microalbuminuria in diabetic patients - a longitudinal study. Acta Endocrinol Suppl (Copenhagen). 1981;242:53-54.

2. Viberti G, Pickup JC, Bilous RW, Keen H, Mackintosh D. Correction of exercise-induced microalbuminuria in insulin-dependent diabetics after 3 weeks of subcutaneous insulin infusion. Diabetes. 1981;30:818-823.

3. Viberti GC, Jarrett RJ, Mahmud U, Hill RD, Argyropoulos A, Keen H. Microalbuminuria as a predictor of clinical nephropathy in insulin-dependent diabetes mellitus. Lancet. 1982;1: $1430-1432$.

4. Benetos A, Rudnichi A, Safar M, Guize L. Pulse pressure and cardiovascular mortality in normotensive and hypertensive subjects. Hypertension. 1998;32:560-564.

5. Lee JL, Kwon SK, Kim SH. Association among C-reactive protein, pulse pressure and ischemic heart disease in patients with continuous ambulatory peritoneal dialysis. Korean J nephrol. 2003;22:102-108.

6. Chae CU, Pfeffer MA, Glynn RJ. Increased pulse pressure and risk of heart failure in the elderly. JAMA. 1999;28:634-639.

7. Vaccarino V, Holford TR, Krumholz HM. Pulse pressure and risk for myocardial infarction and heart failure in the elderly. JACC. 2000;36:130-138.

8. Arulkumaran N, Diwakar R, Tahir Z, Mohamed M, Kaski JC, Banerjee D. Pulse pressure and progression of chronic kidney disease. J Nephrol. 2010;23:189-193.

9. Yasuno S, Ueshima K, Oba K, Fujimoto A, Hirata M, Ogihara T, et al. Is pulse pressure a predictor of new-onset diabetes in high-risk hypertensive patients?: a subanalysis of the Candesartan Antihypertensive Survival Evaluation in Japan (CASE-J) trial. Diabetes Care. 2010;33:1122-1127.

10. Narkiewicz K. Obesity and hypertension-the issue is more complex than we thought. Nephrol Dial Transplant. 2006;21: 264-267.

11. Safar ME. Pulse pressure. arterial stiffness. and microvessels. Hypertension. 2004; 44:121-122.

12. Gasowski J, Fagard RH, Staessen JA, Grodzicki T, Pocock S, Boutitie F, et al. Pulse blood pressure component as predictor of mortality in hypertension: a meta-analysis of clinical trial control groups. J Hypertension. 2002;20:145-151.

13. Sesso HD, Stampfer MJ, Rosner B, Hennekens CH, Gaziano JM, Manson JE, et al. Systolic and diastolic blood pressure, pulse pressure, and mean arterial pressure as predictors of cardiovascular disease risk in Men. Hypertension. 2000;36: 801-807.

14. Berne RM, Levy MN. Cardiovascular Physiology. 6 th ed. Saint Louis: Mosby; 1992. p113-144.

15. Safar ME. Pulse pressure, arterial stiffness, and cardiovascular risk. Curr Opin Cardiol. 2000;15:258-263.

16. Franklin SS, Khan SA, Wong ND, Larson MG, Levy D. Is pulse pressure useful in predicting risk for coronary heart disease? The framingham heart study. Circulation. 1999;100:354-360.

17. Staessen JA, Gasowski J, Wang JG, Thijs L, Hond ED, Boissel JP. Risks of untreated and treated isolated systolic hypertension in the elderly: meta-analysis of outcome trials. Lancet. 2000; 355:865-872.

18. Erdmann E. Microalbuminuria as a marker of cardiovascular risk in patients with type 2 diabetes. Int J Cardiol. 2006; 107:147-153.

19. Raymond $\mathrm{OE}$, Rita $\mathrm{AD}$, Robert $\mathrm{S}$, Mori JK. Relation of reduction in urinary albumin excretion to ten-year cardiovascular mortality in patients with type 2 diabetes and systemic hypertension. Am J Cardiol. 2012;109;1743-1748.

20. Yudkin JS, Jackson CA. Microalbuminuria as predictor of vascular disease in non-diabetic subjects. Lancet. 1988;2:530-533.

21. Pedrinelli R, Dell'Omo G, Penno G, Bandinelli S, Bertini A, Di Bello V, et al. Microalbuminuria and pulse pressure in hypertensive and atherosclerotic men. Hypertension. 2000;35:48-54.

22. Cirillo M, Stellato D, Laurenzi M, Panarelli W, Zanchetti A, De Santo NG. Pulse pressure and isolated systolic hypertension: association with microalbuminuria. The GUBBIO Study Collaborative Research Group. Kidney Int. 2000;58:1211-1218.

23. Park SY, Yoon H, Oh HJ. The association of metabolic syndrome, metabolic syndrome score and pulse pressure in Korean adults: Korea National Health and Nutrition Survey, 2012. J Korea Acad Industr Coop Soc. 2015;9:5660-5667.

24. Parving HH, Persson F, Rossing P. Microalbuminuria: a parameter that has changed diabetes care. Diabetes Res Clin Pract. 2015;107:1-8. 